\title{
Rail-Route Planning Using a Geographical Information System (GIS)
}

\author{
Sandeep Panchal \\ Department of Civil Engineering \\ NIT Hamirpur, \\ Hamirpur, Himachal Pradesh \\ 2290sandy@gmail.com
}

\author{
Asim Debbarma \\ Department of Civil Engineering, \\ NIT Hamirpur, \\ Hamirpur, Himachal Pradesh \\ 2290sandy@gmail.com
}

\begin{abstract}
The aim of this study is to analyse the potential of geographical information system (GIS) in decision making in rail route planning process. The various parameters affecting the alignment of rail route are considered in this study and a feasibility map is prepared considering the cumulative effect of these factors. The factors considered in this study are road network, slope, topographical characteristics and drainage characteristics of study area. Each parameter is given weights according to analytic hierarchy process (AHP) in GIS environment. The layers of parameters affecting the feasibility of route are overlaid in GIS environment to find a feasibility map. Feasibility map is divided into five categories i.e. very low, low, moderate, high and extremely feasible on the basis of feasibility index.
\end{abstract}

Keywords-route; planning; AHP; GIS; high speed rail; transport

\section{INTRODUCTION}

Route planning is a very difficult task in hilly regions. The uncertainty of various factors which affect the route alignment makes this process more complicated. Alignment of a route is to be decided by balancing the economical and engineering considerations. Conventional processes of route planning are very difficult and the results are not much accurate. It is difficult to find the cumulative effect of the factors like slope, drainage pattern of area and topographical characteristics of study area. Transportation and highway engineering is one field which has been affected by developments in GIS aspects, as spatial variables including environment, topography, built-up areas, land use/land cover, can be easily modeled. The first concept of GIS application in rail track planning developed from location map through digitizing, geo-referencing and entering considered data. The factors considered are weighted according to GISs' criteria and importance with the help of different methods. The weighted factors are now standardized and overlaid in the proposed map by the help of Arc GIS tools. So the use of GIS application has very much important role to take place in the development and making of a new rail track or road at any type of topological conditions on earth. Geographical information system (GIS) is a very efficient tool in route planning. It is easy to model the various factors affecting the route alignment in GIS environment [1]. The inputs in GIS environment can be varied to change the output until the planner is satisfied with the results. Effect of engineering, social, economic and environmental factors can be considered in route planning of highways [2]. Route selection is a critical first step in the process of design and construction and has a potentially significant impact to the construction and environment of the area.

The various methods of route alignment in GIS can be considered and a best method can be found out by comparing them [3]. Multi-criteria decision analysis is a good way to consider the effect of economic and engineering factors. COSIMA is a model that considered the cost benefit analysis as a factor and then modeled the route alignment in GIS environment [4]. The methods suggested by various researchers are applied in plain terrains but the study area considered in this study is hilly. The study area lies in lower Shiwaliks in India. During the past decade the study area has become a development hub. The main assumption in this study is that the rail route should align as near as possible to the state highway 32 (SH-32). So, the study is restricted up to $1 \mathrm{Km}^{2}$ area along SH-32. The reason behind this assumption is that the important places and cities are along SH-32 and also that the construction site will thus be easily accessible for the transporting of raw materials. In nutshell, the various factors affecting the alignment of rail route are considered in this study. These factors are digitized and each factor is represented by a layer in GIS environment. These factors and their subfactors are given weightage according to analytic hierarchy process. The reclassed layers are overlaid to get the final feasibility map. The feasibility map is divided into five parts according to the feasibility index. The feasibility map is an output of cumulative effect of factors affecting route feasibility.

\section{MATERIAL AND METHODS}

The various parameters considered in this study are slope, nearness to important places, nearness to stream, nearness to routes, lithology and properties of soil in study area. Analytic hierarchy process is used to know the relative importance of each criterion. 


\section{A. Parameters of Route Feasibility}

The various factors affect route planning in different ways. Each factor and its effect on route alignment are explained below.

\section{1) Slope}

The proposed railway line should not go from the areas which have high slope. If the slope in the study area is more than $25^{\circ}$, then it affects the economy of the project as the chances of landslides near railway track increases. Slope layer of the study area is shown in Figure 1.

2) Nearness to Important Places:

The proposed railway line should be near to the important cities or villages because of accessibility concerns. If the railway facility is much away from the important places, it will be difficult to use. Figure 2 shows the nearness to important places.

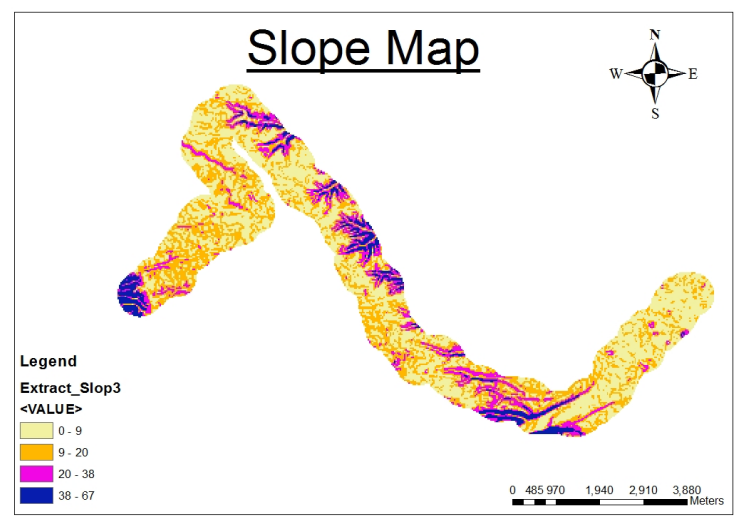

Fig. 1. Slope Layer

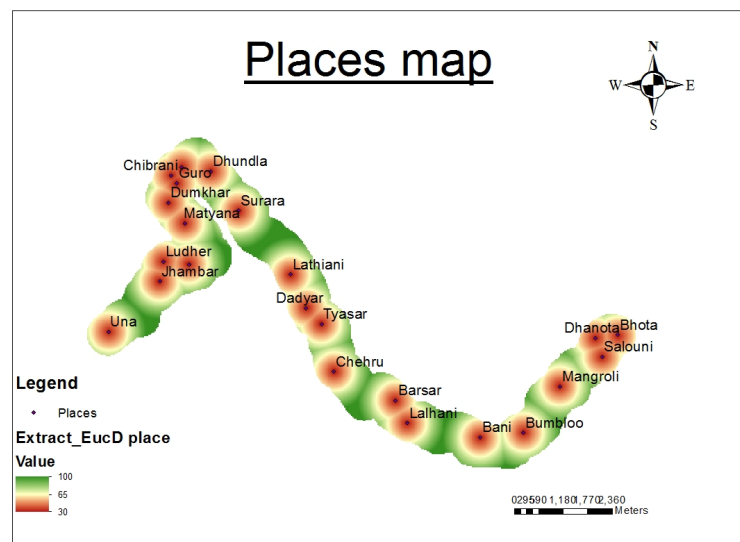

Fig. 2. Nearness to Places

\section{3) Nearness to Streams}

The proposed railway section should not be near to streams or high water level. High water level near the construction site is not preferred because it causes problem during construction. Figure 3 shows the nearness to streams.

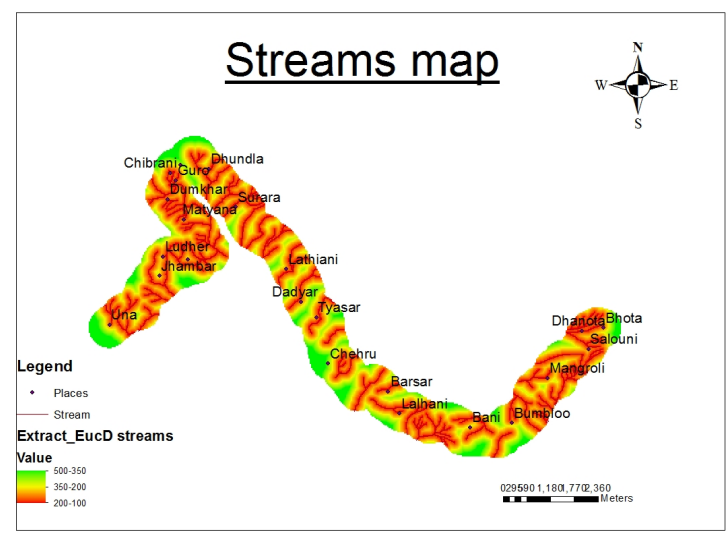

Fig. 3. Nearness to Streams

4) Gradient

Gradient of the area should be gentle if possible. The lower gradient values are preferred from the economic point of view.

5) Lithology

The rocks encountered in the hilly region are a big challenge to deal with. Alluvium can be cut easily but boulder and shales are hard to cut. So, it is preferred that the route should go through soft rocks. Figure 4 shows lithology of the study area.

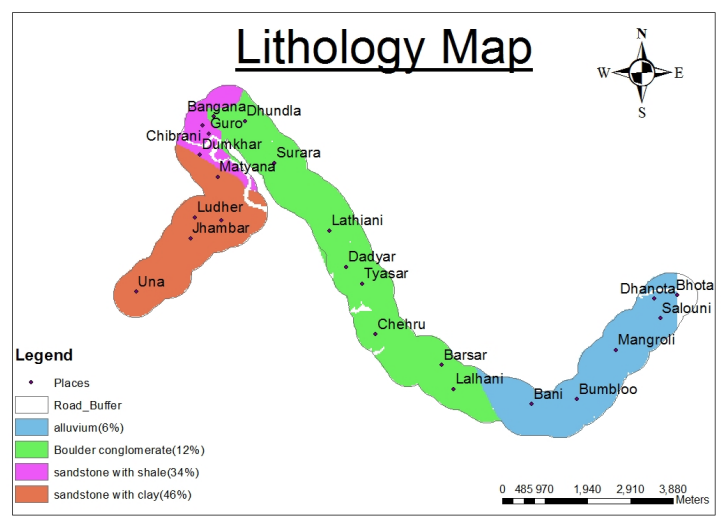

Fig. 4. Lithology of Area

6) Type of Soil

The top soil should be soft but there should be firm strata beneath the soil so that the foundation can rest on it. So, soil is also taken as a factor which affects the feasibility of rail route.

\section{7) Nearness to Route}

The proposed railway track should be well connected. So, nearness to routes is also an important factor considered in this study. Figure 5 shows the nearness to route. 
8) Landuse/Landcover

The landuse and landscover of the study area is another important factor that affects the route planning process. The route should go through barren land instead of agricultural and forest area.

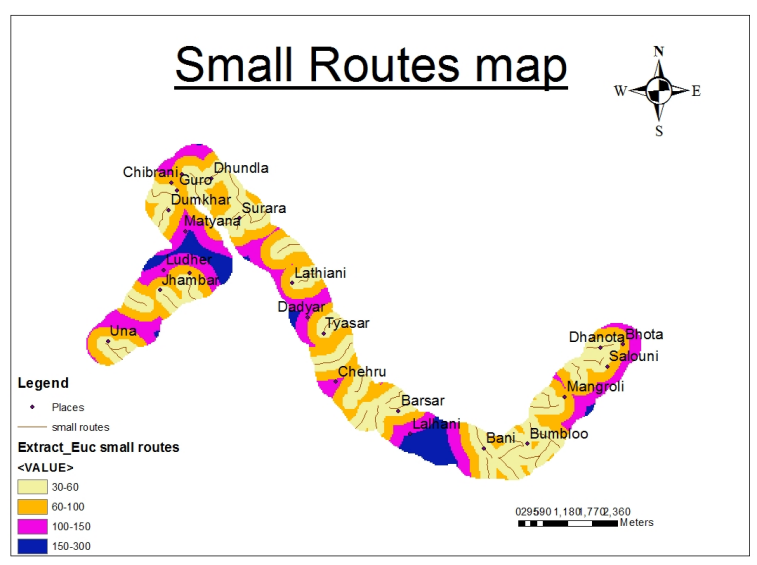

Fig. 5. Nearness to Routes

\section{B. Analytic Hierarchy Process(AHP)}

Analytic hierarchy process is a multi-criteria decision making technique which is used to find the relative importance of criteria [5]. A 1-9 scale is used for calculating relative importance of the criteria like slope, lithology etc. Table I shows the scale of reference proposed [5]. The preference criteria given in Table I are used to compare the various parameters.

TABLE I. SCALE OF REFERENCE

\begin{tabular}{|c|c|c|}
\hline Scale & $\begin{array}{l}\text { Degree of } \\
\text { Preference }\end{array}$ & Explanation \\
\hline 1 & Equal & $\begin{array}{l}\text { Two activities contribute equally to } \\
\text { an objective }\end{array}$ \\
\hline 3 & Moderate & $\begin{array}{c}\text { Experience and judgment slightly } \\
\text { to moderately favour one activity } \\
\text { over the other }\end{array}$ \\
\hline 5 & Strong & $\begin{array}{l}\text { Experience and judgment strongly } \\
\text { favour one activity over other. }\end{array}$ \\
\hline 7 & Very Strong & $\begin{array}{c}\text { Experience and judgment very } \\
\text { strongly favour one } \\
\text { activity over other }\end{array}$ \\
\hline 9 & Extreme & $\begin{array}{l}\text { The one activity affect the } \\
\text { objective with the highest degree } \\
\text { that is possible }\end{array}$ \\
\hline $2,4,6,8$ & $\begin{array}{c}\text { Intermediate } \\
\text { value }\end{array}$ & $\begin{array}{c}\text { Used to present the compromise } \\
\text { between values } \\
1,3,5,7,9 \\
\end{array}$ \\
\hline Reciprocal & Opposites & Used for inverse comparison \\
\hline
\end{tabular}

Consistency Ratio (CR) is calculated to measure the consistency of the solution. If the value of $\mathrm{CR}<10 \%$, then the ratio is defined as reasonable level of consistency. It means that the values assigned to the parameters are considered correct. If the value of $\mathrm{CR}$ is more than $10 \%$ then the preferences are to be revised to get the consistence result. When CR value is less than $10 \%$ then the results are considered as consistent and can be used for the analysis. The final weightage to be assigned to the criteria like slope, nearness to streams etc. are found by their relative comparison. The solution is checked for consistency. If it is found consistent, then the calculated weights can be assigned to each criteria and sub-criteria.

\section{Role of GIS}

The various parameters affecting the feasibility of rail route are converted in layers using GIS. Slope layer can be driven from the digital elevation model (DEM) of the study area. The maps of the study area are collected from Survey of India (SOI). The maps are scanned and imported in ArcGIS 10. The maps are georeferenced and the factors like streams; places etc. are digitized using linear and polygon tools. The digitized data is converted into raster format. All the layers prepared in GIS environment are given weightage calculated using AHP. The layers prepared in GIS are overlaid using the weighted overlay. As the layers are overlaid, a final map is formed by the combination of various layers. The combination of weightage of layers is called feasibility index. The output map which is the output of the combination of layers is based on the feasibility index and shows the cumulative effect of the factors which are considere. The final map can be reclassed into five parts i.e. lest feasible, low feasible, moderately feasible, highly feasible and extremely feasible.

\section{RESULTS AND DISCUSSION}

The final result of the study is a feasibility map which shows the feasibility of rail route with different colours. It is found that the study area in the beginning of $\mathrm{SH}-32$ is extremely feasible for the construction of railway line. It is because this area is almost flat and there are not much hills. The gradient is small and also the slopes in the area are gentle. About $35-40 \%$ of the area is found to be suitable for the alignment of the rail route. The terrain and land-use characteristics of the area are supporting the construction of railway line. There is almost $20 \%$ area which is least and low feasible for rail route construction. The terrain and lithology of the area proved challenging. It is difficult to construct the rail route in the least feasibility region due to its challenging terrain conditions. Figure 6 shows the feasibility map. The most feasible route in the study area should be through the best options according to the feasibility map. A final route is also proposed according to the feasibility map. Figure 7 shows a proposed feasible route. The most feasible route passes through the best alternative which is available at any point.

\section{CONCLUSIONS}

It can be concluded from this study that geographical information system (GIS) can be used for route feasibility studies. It is easy to model the various factors affecting route feasibility in GIS environment. The advantage of using the GIS for route feasibility studies is that the planner can vary the input to change the output. The inputs can be varied until the planner gets satisfied by the results. The main limitation of this study is that the output of the study depends upon the accuracy 
of the parameters. If the input is erroneous the output will also be erroneous. The output of the study can be modified by considering the other factors which affect the route feasibility.

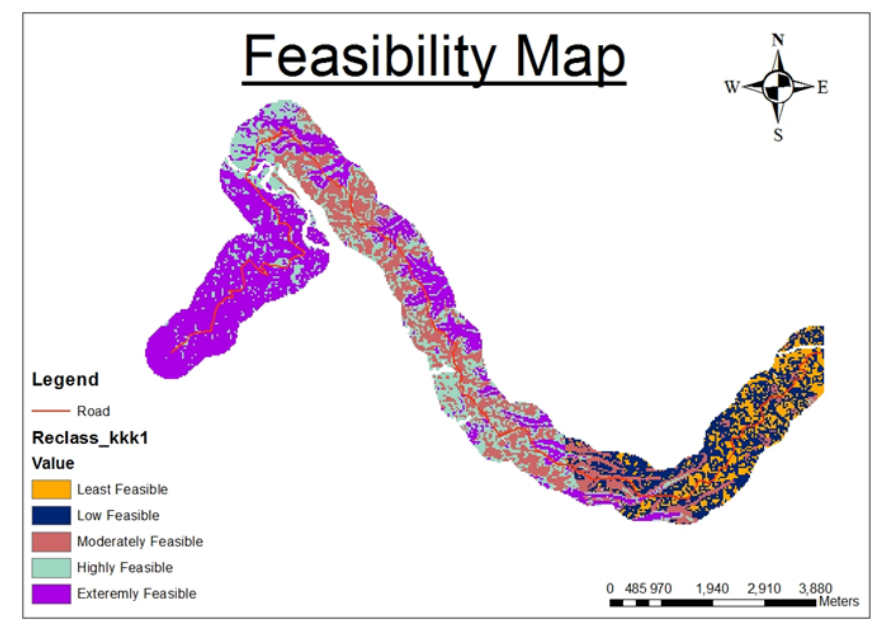

Fig. 6. Feasibility Map

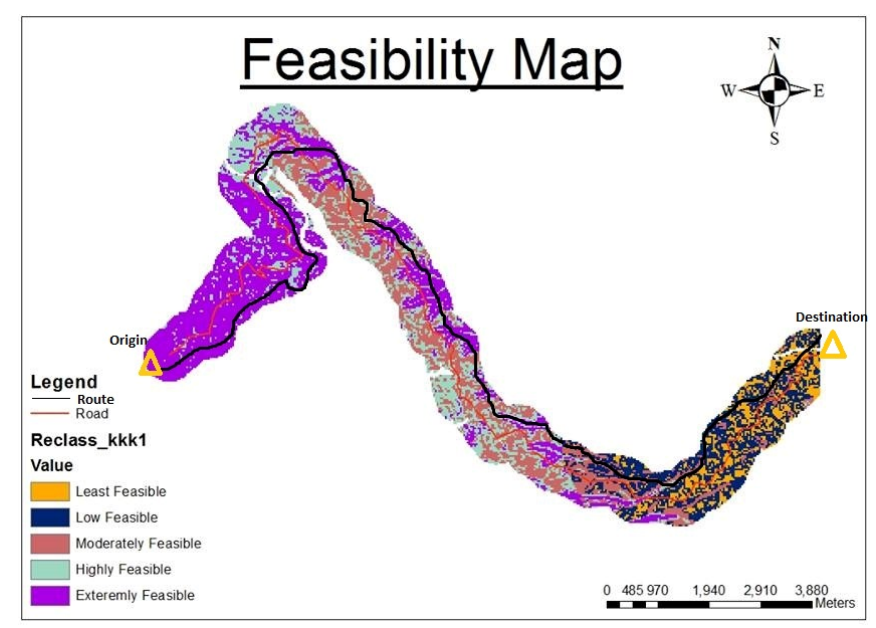

Fig. 7. Most Feasible Route

\section{ACKNOWLEDGMENT}

Authors are thankful to Dr. Vijay Shankar Dogra, Head of Department, Civil Engineering, NIT Hamirpur for providing research friendly environment in the institute. Authors are also thankful to the Department of Civil Engineering, NIT Hamirpur for providing the resources for the research.

\section{REFERENCES}

[1] G. Della Acqua, "Using Fuzzy Inference Systems to Optimize Highway Alignments", International Journal for Traffic and Transport Engineering, Vol. 2, No. 1, pp. 44-59, 2008

[2] R. Mateus, J. A. Ferreira, J. Carreira, "Multi criteria decision analysis (MCDA): Central Porto high-speed railway station", European Journal of Operational Research, Vol. 187, pp. 1-18, 2008

[3] J. Barzilai, "Deriving Weights from Pair wise Comparison Matrices", Journal of the Operational Research Society, Vol. 48, No. 12, pp. 12261232,1997

[4] I. Ambrasaite, M. B. Barfod, K. B. Sallin, "MCDA and Risk Analysis in Transport Infrastructure Appraisals: The Rail Baltica Case", Proscenia Social and Behavioral Sciences, Vol. 20, pp. 944-953, 2011

[5] T. L. Saaty, "How to Make a Decision: The Analytic Hierarchy Process", European Journal of Operation Research,Vol. 48, No.1, pp. 926, 1990

[6] T. Kara, M.Cengiz Savas, "Design and Simulation of Decentralized Railway Traffic Control System", Engineering, Technology and Applied Science Research, Vol. 6, No. 2, pp. 945-951, 2016

[7] A. Predo, M. Ronkko, S. Pickl, M. Kolehmainen, "GIS-Based Route Planning for HAZMAT Transportation", IFIP Advances in Information and Communication Technology, Vol. 413. Springer, Berlin, Heidelberg, 2013

[8] Y. H. Wu, H. Miller, M. C. Hung, "A GIS-based decision support system for analysis of route choice in congested urban road networks", Journal of Geographical Systems, Vol. 3, No. 3, pp. 3-24, 2001

[9] R. Huang, "A schedule-based pathfinding algorithm for transit networks using pattern first search", GeoInformatica, Vol. 11, No. 2, pp. 269-285, 2007

[10] C. Macharis, A. De Witte, L. Turcksin, "The Multi-Actor Multi-Criteria Analysis (MAMCA) application in the Flemish long-term decision making process on mobility and logistics", Transport Policy, Vol. 17, No. 5, pp. 303-311, 2007

[11] I. Ambrasaite, M. B. Barfod, K. B. Sallin, "MCDA and Risk Analysis in Transport Infrastructure Appraisals: The Rail Baltica Case", Procedia Social and Behavioral Sciences, Vol. 20, pp. 944-953, 2011

[12] X. Chen, M. Zhang, "High-Speed Rail Project Development processes in the United States and China", 2010,Transportation Research Record, No. 2159, pp. 9-17, 2010 